\title{
A Note on the Variability of Temperature as Indicated by Rocketsonde Thermistors
}

\author{
Alvin J. Milier \\ National Meteorological Center, ESSA, Hillcrest Heights, Md.
}

23 July 1968 and 16 September 1968

\section{Introduction}

While there has been considerable discussion in the recent literature concerning the accuracy of temperatures measured by certain rocketsonde thermistors
(Wagner, 1964; Beyers and Miers, 1967; Lindzen, 1967; Ballard, 1967; Thompson and Keily, 1967; Thompson, 1968; Ballard, 1968), this literature has tended to be concerned more with the theoretical than

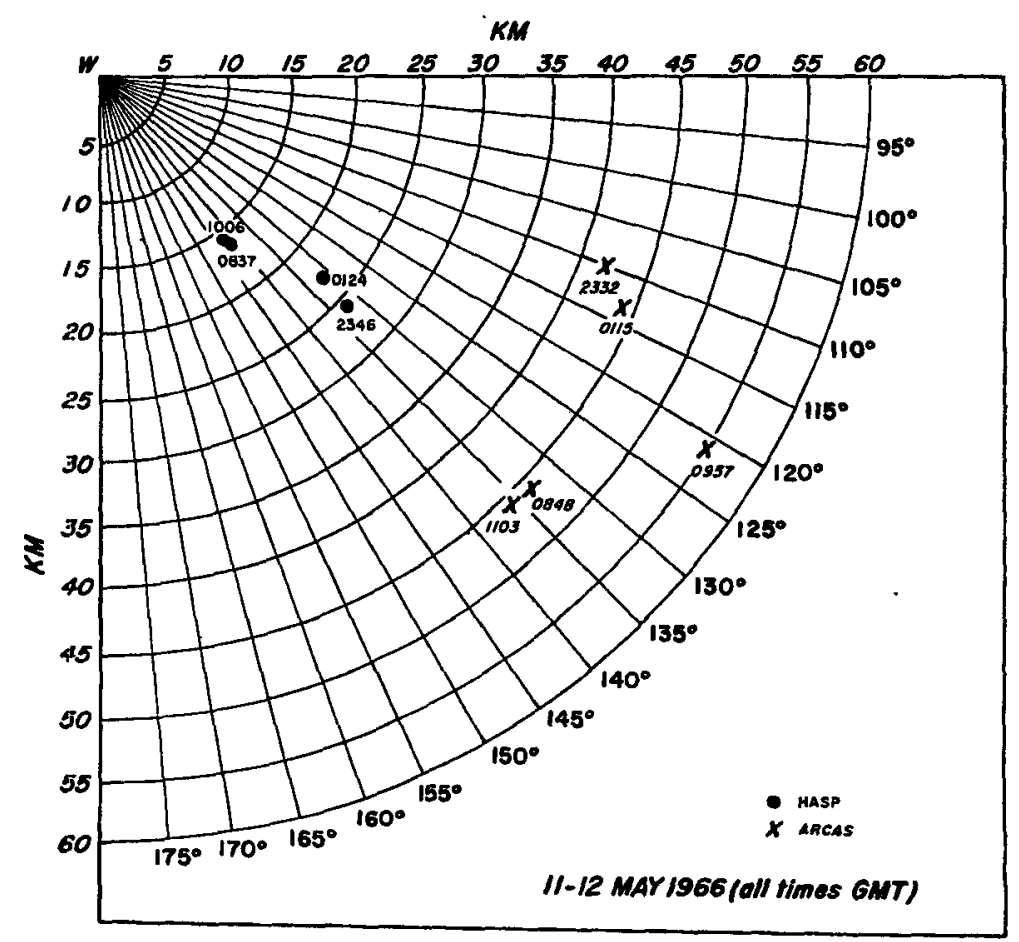

FIG. 1. Launch times and locations of rocket soundings with respect to Wallops Island. 


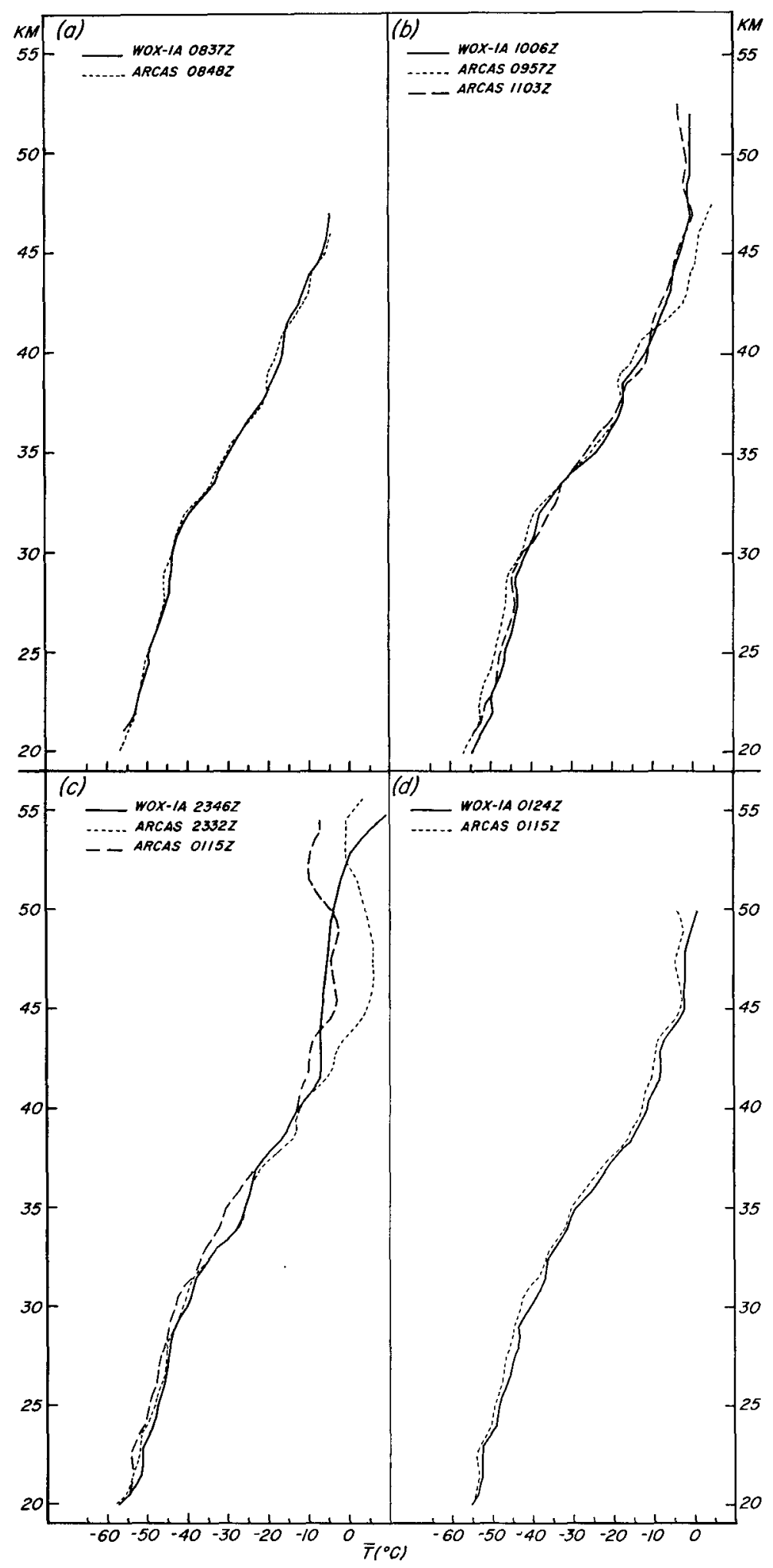

FIG. 2. Comparison of temperature profiles obtained from the rocket sounding of Fig. 1. See text for discussion. 
with the practical aspects of the problem. That is to say that the emphasis has been on determining a technique for "correcting" the temperature measurements for such factors as dynamic heating, radiation effects, etc. (Ballard, 1967). At the same time, however, users of the data are occasionally faced with certain inconsistencies in the measured temperatures that cannot be resolved by any of the correction schemes yet devised. The purpose of this note is to present a typical example of the type of features we encounter, and to comment on the applicability of the data.

The data source for this study was an experiment conducted on 11-12 May 1966 at Wallops Island, Va., during which several Arcasonde 1A and W0X-1A instruments (Finger and Woolf, 1967) were launched within a short time and distance from one another. Temperatures were determined with $1 \mathrm{C}$ departure from linearity employed as the criterion for a significant level. Since our interest centered on the general temperature differences that existed, all temperature profiles were smoothed by a 1-2-1 weighted average smoothing at $500-\mathrm{m}$ intervals. The effects of this smoothing function on the small-scale structure has been discussed by Miller et al. (1968).

\section{Results}

Fig. 1 indicates the launch time and general location with respect to Wallops Island of each instrument used in this study. The instrument pairs are characterized by a time separation of about $12 \mathrm{~min}$ and a spatial separation of about $30 \mathrm{~km}$.

The smoothed temperature profiles are depicted in Fig. 2 and, as is clearly evident, there is considerable disagreement not only between the Arcasondes and the WOX-1A's, but also between the Arcasondes. Sections $\mathrm{b}$ and $\mathrm{c}$, for example, indicate temperature differences as great as $5-8 \mathrm{C}$ between the earlier and the later soundings with the largest discrepancies at the higher altitudes. This circumstance immediately suggested that the warmer temperatures might be due to dynamic heating effects (usually considered to be the major source of error at these altitudes), but this was not borne out by investigation. The fall velocity of the 0957 GMT Arcasonde was less than that of the 1103 GMT Arcasonde above about $40 \mathrm{~km}$ and approximately coincident below this altitude. The fall rates for the 2332 and 0115 observations were approximately equal.

Unfortunately, the radars lost track of the 0115 observation between 45 and $55 \mathrm{~km}$ and the heights associated with the given temperatures had to be interpolated in this region. The error in height is expected to be on the order of $200 \mathrm{~m}$. While this inhibits an accurate comparison of the trends in the temperature profiles, the general discrepancy between the two Arcasondes is not invalidated because the high altitude 0115 temperatures are consistently colder than the 2332 temperatures and there is no apparent way by which they can be made coincident.

In contrast to these two examples, however, the 0837 and 0848 profiles (section a) indicate fairly good agreement with each other, the maximum difference being about $1.5 \mathrm{C}$. The 0115 and 0124 observations (section d), while exhibiting a similar trend, include a consistent bias with the WOX-1A warmer than the Arcasonde by about $1-2 \mathrm{C}$.

\section{Discussion}

As stated above, our point in presenting these results is that we cannot explain them by the theories that have been developed to date and we feel that the question of instrument reliability remains to be resolved. From the practical point of view, if the temperature differences are due to instrument malfunction, then the instruments may be unacceptable for routine observational use. On the other hand, if these differences are real and due to an inherently large variability in the atmosphere, then we must ask what does a particular sounding represent.

Acknoweledgments. This work was performed with the support of the National Aeronautics and Space Administration, under its EXAMETNET program. We gratefully acknowledge the efforts of all personnel who made the experiment possible.

\section{REFERENCES}

Ballard, H. N., 1967: The measurement of temperature in the stratosphere and mesosphere. J. Appl. Meteor., 6, 150-163.

- 1968: Reply (on the errors of thin-film mounted rocketsonde thermistors). J. Appl. Meteor., 7, 306-310.

Beyers, N. J., and B. T. Miers, 1967 : Reply (on the consistency of thermistor measurement of upper air temperatures). $J$. Almos. Sci., 24, 319-320.

Finger, F. G., and H. M. Woolf, 1967: Diurnal variation of temperature in the upper stratosphere as indicated by a meteorological rocket experiment. $J$. Atmos. Sci., 24, 230-239.

Lindzen, R. S., 1967 : On the consistency of thermistor measurements of upper air temperatures. J. Atmos. Sci., 24, 317-318.

Miller, A. J., H. M. Woolf and F. G. Finger, 1968: Small-scale wind and temperature structure as evidenced by meteorological rocket systems. J. Appl. Meteor., 7, 390-399.

Thompson, D. C., 1968: On the errors of a thin-film mounted rocketsonde thermistor. J. A ppl. Meteor., 7, 306.

-- , and D. P. Keily, 1967 : The accuracy of thermistors in the measurement of upper air temperatures. J. Appl. Meteor., 6, 380-385.

Wagner, N. K., 1964: Theoretical accuracy of a meteorological rocketsonde thermistor. J. Appl. Meleor., 3, 461-469. 